\title{
Combined RBFN based MPPT and $d$-axis stator current control for permanent magnet synchronous generators
}

\author{
Tuan Ngoc Anh Nguyen ${ }^{1}$, Duy Cong Pham ${ }^{2}$, Luu Hoang Minh ${ }^{3}$, Nguyen Huu Chan Thanh ${ }^{4}$ \\ ${ }^{1,2}$ Faculty of Electrical Engineering, Industrial University of Ho Chi Minh City, Ho Chi Minh City, Vietnam \\ ${ }^{3}$ Faculty of Electrical \& Electronics Engineering, Ho Chi Minh City University of Transport, Ho Chi Minh City, Vietnam \\ ${ }^{4}$ Faculty of Aeronautical Electronics Telecommunications Engineering, Vietnam Aviation Academy, Ho Chi \\ Minh City, Vietnam
}

\begin{tabular}{l} 
Article Info \\
\hline Article history: \\
Received May 22, 2021 \\
Revised Sep 23, 2021 \\
Accepted Oct 3, 2021 \\
\hline
\end{tabular}

\section{Keywords:}

Constant stator flux-linkage

Differential evolution

Maximum power point tracking

Permanent magnet synchronous generator

Radial basis function neural

networks

Unity power factor

Zero $d$-axis stator current

\section{Corresponding Author:}

Ngoc Anh Tuan Nguyen

Faculty of Electrical Engineering

Industrial University of Ho Chi Minh City

12 Nguyen Van Bao Street, Go Vap District, Ho Chi Minh City, Vietnam

Email: nguyenngocanhtuaniuh@gmail.com

\begin{abstract}
This paper proposes a new radial basis function neural network maximum power point tracking controller based on a differential evolution algorithm for machine side converter of permanent magnet synchronous generator wind turbine under variable wind speed. Direct axis stator current control methods of permanent magnet synchronous machine are reviewed shortly. A combined radial basis function neural network-based network maximum power point tracking method and $d$ axis stator current control techniques including zero $d$ axis stator current, unity power factor, and constant stator flux-linkage have been implemented to control the machine side converter of permanent magnet synchronous generator wind turbine. The dynamic performance of the proposed approach is assessed under different operating conditions through a simulation model based on MATLAB. It has been seen that the radial basis function neural network controller can not only track well the maximum power point but also can be reduced costly.
\end{abstract}

This is an open access article under the CC BY-SA license.

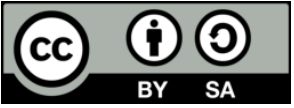

\section{INTRODUCTION}

Nowadays, wind energy is popular clean energy in the world due to its own merit are pollution freezes, cost reduction and high reliability [1], [2]. Wind energy is interested in both industrial and academic fields [3] because of technological advancements and support programs of the government in order to obtain green energy strategies for sustainable development [4]

Generally, the main wind-energy conversion system consists of a wind alternator, a gearbox, a transformer and a back-to-back (BTB) converter [5], [6]. Compared to other types, the permanent magnet synchronous generator (PMSG) is popular in current uses because of high performance, high reliability, and gearless configuration [7] shown in Figure 1. Accordingly, objective of improving performance, efficiency and reduce cost, the variable speed wind turbine is needed to operate at the MPPT under variable wind speed [8]. The drawback of the conventional MPPT method such as tip speed ratio (TSR) [9] are errors in processing measurement, cost and difficulty in implementation [10]. 


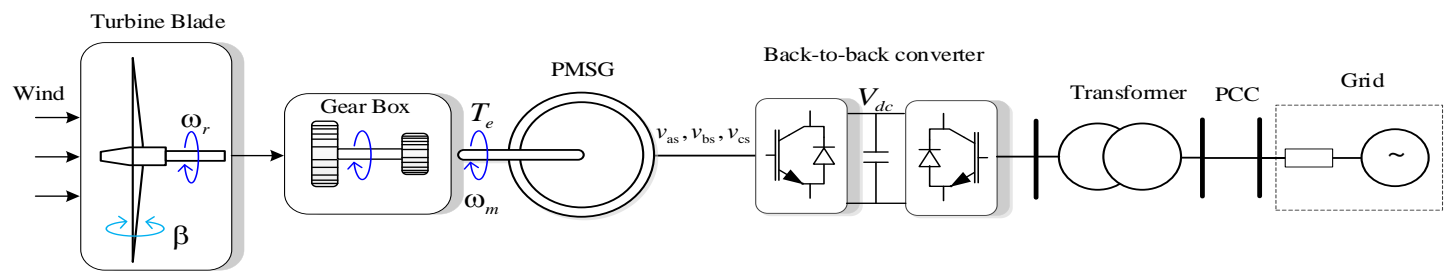

Figure 1. Configuration of PMSG wind turbine

Likewise, the demerit of optimal controller [11], [12] are the saturation effect and the disturbance on the input voltage of the converter. Besides, sliding mode control [13], nonlinear control [14] and fuzzy control [15] or robustness control [16] are popularly used due to its highly efficient but its disadvantage is failed to track maximum power point (MPP) in the rapidly changing conditions. In the same way, the drawback of the maximum electrical power tracking method and a maximum mechanical power tracking method [17] or the extreme seeking method [18] is depended on the parameters of the system and maybe entrapped in the global maximum. Among the adaptive hybrid intelligent control [19] and the expert control system [20], the DE algorithm [21] has received the most attention because of the best effective [22] and exact tracking maximum power point [23]. Until now, the DE algorithm has never been implemented in PMSG wind turbines. Further, the Radial Basis Function Networks (RBFNNs) [24], [25] based MPPT method is proposed to design [26] and implement [27] for PMSG wind turbine because of high performance, accuracy, and convergence. Moreover, the $d$-axis stator current control techniques [28] such as zero d-axis stator current (ZDC), unity power factor (UPF) and constant stator flux-linkage (CSFL) have been interested in improving performance and reduced cost because of hardware less. Currently, these $d$-axis stator current control techniques have only been applied to control for the motor. In this paper, the study applies these techniques with the correction to control for MSC of PMSG. Based on the achieved results, the main contribution of this work can be outlined as follows; i) DE algorithm based MPPT is proposed for PMSG wind turbine; ii) design and implementation of RBFNN for the zero-approximation error of the DE algorithm based MPPT; iii) combined radial basis function neural network based MPPT method and $d$ axis stator current control techniques (ZDC, UPF and CSFL) have been successfully applied for the control of the MSC of PMSG wind turbine.

This article is organized as follows: section 2 interprets in detail of wind turbine conversion power. Section 3 describes the MPPT method. Section 4 shows the stator current control techniques. Section 5 presents and explains the simulation results. Finally, conclusions.

\section{DYNAMIC MODELING OF PMSG WIND TURBINE SYSTEM}

\subsection{Wind turbine model}

The mechanical output power of the wind turbine is given by (1),

$$
P_{m}=\frac{1}{2} \rho \pi R^{2} C_{p}(\alpha, \beta) v_{w}^{3}
$$

where $R$ is the turbine radius $(\mathrm{m}), \rho$ is the air density $\left(\mathrm{kg} / \mathrm{m}^{3}\right), v_{w}$ is the wind speed $(\mathrm{m} / \mathrm{sec}), C_{p}$ is the power coefficient function, $\alpha$ is the tip speed ratio and $\beta$ is the blade pitch angle.

The tip speed ratio and and power coefficient are expressed,

$$
\alpha=\frac{\omega_{t}}{v_{w}} R
$$

where $\omega_{t}$ represent angular speed of rotor

$$
C_{p}(\alpha, \beta)=c_{1}\left(\frac{c_{2}}{\alpha_{i}}-c_{3} \beta-c_{4}\right) e^{\left(-\frac{c_{5}}{\alpha_{i}}\right)}+c_{6} \alpha
$$

where the approximated coefficient values $c_{1}-c_{6}$ are given in Table 3 .

$$
\alpha_{i}=\left(\frac{1}{\alpha+0.08 \beta}-\frac{0.035}{1+\beta^{3}}\right)^{-1}
$$

The relationship between turbine power and wind speed under variable wind speed demonstrates in Figure 2. The turbine power at a certain wind speed is possible at a maximum, which is called optimum wind 
speed. The blue curve is described as the optimal tracking curve. The turbine is required to operate at an optimal tip speed ratio for maximum power. It can be done by driving the turbine's rotational speed in order that it continuously rotates at the optimum speed [2]. The operational zone within a wind speed range that is restricted between connected wind speed ( $v_{w}$ cut-in) and disconnected wind speed ( $v_{w}$ cut-out) affect to the captured wind power. Otherwise, wind turbines are required to stop operating above connected wind speed ( $v_{w} c u t$-in) or below disconnected wind speed $\left(v_{w}\right.$ cut-out) because of protection conditions. The turbine has to stop for protection of the wind turbine as well as generator if out of this range. The wind turbine's rated power $\left(P_{\text {rated }}\right)$ is determined by the wind speed $\left(v_{\text {rated }}\right)$. Then, it can be divided into 4 main regions and classified as follows [9]; i) wind turbines must be stopped and disconnected from the grid to avoid the generator implements in region 1 and 4 , which is below ( $v_{w}$ cut-in) and above $\left(v_{w}\right.$ cut-out); ii) the second region is in between $\left(v_{w}\right.$ cut-in) and $\left(v_{w}\right.$ rated $)$ which a wind turbines controller implements the MPPT method below rated wind speed to achieve the optimal power during the variable wind speed; iii) the third region is in between ( $v_{w}$ rated) and ( $v_{w}$ cut-out) where the pitch controller is used to limit the mechanical power generation and to keep wind turbines in safe operation.

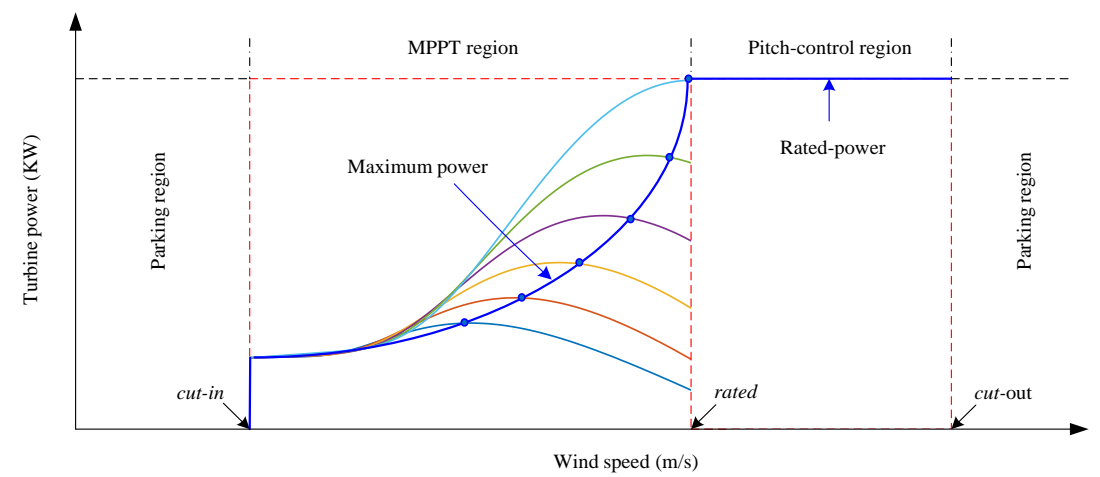

Figure 2. Wind energy conversion system operating regions

\subsection{Permanent magnet synchronous generator model}

The equivalent circuit model of the PMSG is depicted in Figure 3. In the $d q$ reference frame, the stator voltage of PMSG wind turbine is given by [3]. In this article presents surface mounted alternator.

$$
\left\{\begin{array}{l}
u_{\mathrm{ds}}=R_{s} i_{\mathrm{ds}}+L_{\mathrm{ds}} \frac{d i_{\mathrm{ds}}}{d t}-\omega_{r} L_{\mathrm{qs}} i_{\mathrm{qs}} \\
u_{\mathrm{qs}}=R_{s} i_{\mathrm{qs}}+L_{\mathrm{qs}} \frac{d i_{\mathrm{qs}}}{d t}-L_{\mathrm{ds}} i_{\mathrm{ds}} \omega_{r}+\lambda_{r} \omega_{r}
\end{array}\right.
$$

Where $u_{d s}$ and $u_{q s}$ are the stator terminal voltages on $d, q$ axis, respectively, $i_{d s}$ and $i_{q s}$ are stator current on $d, q$ axis, $L_{d s}$ and $L_{q s}$ are the synchronous inductances of the generator on $d, q$ axis, $R_{s}$ is stator resistance, $\omega_{r}$ is the electrical angular velocity of the rotor, $\lambda_{r}$ is the amplitude of the flux linkage. The generator electromagnetic torque, the active and reactive powers at generator terminals are given

$$
\begin{aligned}
& T_{e}=\frac{3}{2} \rho i_{\mathrm{qs}} \lambda_{r} \\
& {\left[\begin{array}{l}
P \\
Q
\end{array}\right]=\frac{3}{2} u_{\mathrm{ds}}\left[\begin{array}{l}
i_{\mathrm{ds}} \\
i_{\mathrm{qs}}
\end{array}\right]+\frac{3}{2} u_{\mathrm{qs}}\left[\begin{array}{c}
i_{\mathrm{qs}} \\
-i_{\mathrm{ds}}
\end{array}\right]}
\end{aligned}
$$

Where $T_{e}$ is the torque, $p$ is the number of pole pairs

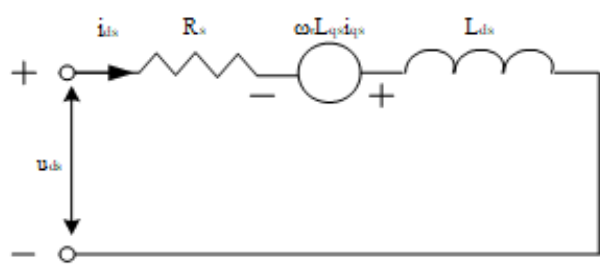

(a)

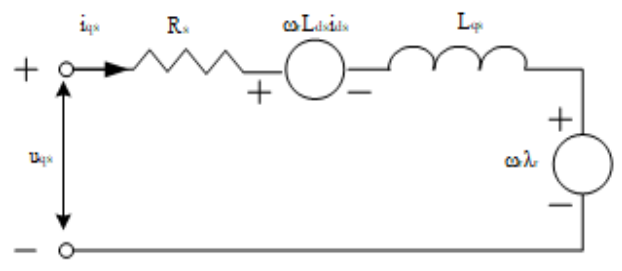

(b)

Figure 3. Equivalent circuit model of the PMSG: (a) $d$-axis circuit; (b) $q$-axis circuit 


\section{MPPT}

In order to increase energy conversion efficiency in varying the speed, WECS need peak power extraction because it is important. The MPPT control tries to achieve the maximum possible power at a $v_{w}$ certain value of the wind. The maximum power point (MPP) trajectory depends on the wind speed. The operational zone of the MPPT control is a period from cut-in wind speed to rated wind speed, as seen in the graph of this curve in Figure 2.

\subsection{Conventional MPPT method}

In past years, many MPPT methods have been studied and improved [2], [3]. There are many different merits and demerits in each of them. In a way that the most popular method is employed the tip speed ratio (TSR) technique [17] that uses (2). Thus, this control technique's own flaw is that it necessitates the use of a wind-speed measurement gadget and the pre-determined value of the best tip speed ratio for converting wind velocity measurements into their corresponding optimal speed reference [18]. This also increases the cost of the system [19].

\subsection{Differential evolution-based MPPT}

Since 1995, DE was arguably one of the first technical present by R. Storn and K. V. Price for global optimization over continuous search space [21], in which its configuration was optimal functions in a continuous $\mathrm{N}$-dimensional region. Each individual in the population is an $\mathrm{N}$-dimensional vector that represents a problem solution. DE depends on taking the distinction vector between two types and including a scaled sort of the distinction vector to a third individual to make another applicant arrangement [22].

The process creates a new candidate solution such as a mutant vector is created by joining three arbitrarily chose vectors from the number of inhabitants in vectors barring the objective vector. This consolidating cycle of three haphazardly chose vectors to shape the mutant vector and a multiplier which is the fundamental boundary of the DE calculation [23]. This results in a mutant that might be accepted into the population as a new candidate solution. There are two generally utilized hybrid techniques in DE: binomial hybrid and exponential hybrid. The fittest vector in each pair is kept for the next DE generation, and the least fit is discarded. The basic DE algorithm for an N-dimensional issue is depicted in Table 1 and these parameters are simulated in MATLAB. The flowchart for DE algorithm is illustrated in Figure 4.

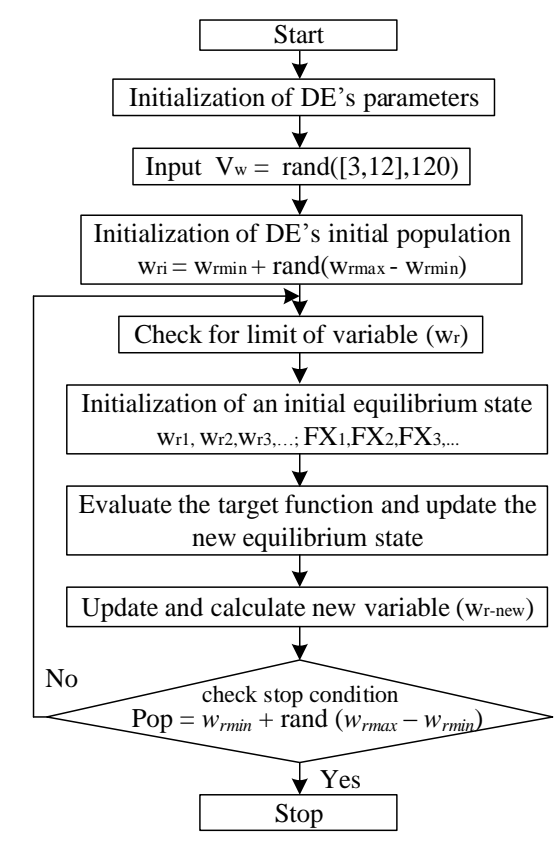

Table 1. The parameters of DE

\begin{tabular}{cc}
\hline Description & Value \\
\hline Particle number of a generation, $\mathrm{N}_{\text {pop }}$ & 30 \\
Maximum number of generations, iter & 50 \\
Cross & 0.2 \\
Scaling factor lower bound & 0.2 \\
Scaling factor upper bound & 0.8 \\
\hline
\end{tabular}

Figure 4. Flowchart for differential evolution

\subsection{Proposed the RBFNN based MPPT method}

In this section is proposed a model of straightforward neural network architecture, which has only one hidden layer and is utilized in many application areas. It is named Radial Basis Function Neural Networks (RBFNN). An RBFNN based on MPPT method is designed to enable controlling MPPT without 
knowing the air density or the mechanical parameters of the turbine. The condition is justified because the goal of this study is to track the maximum power point and the reference model provided by (1) justifies the demand [24], [25]. The network is trained offline using data acquisition which is implemented by using DE that as illustrated in Figure 5.

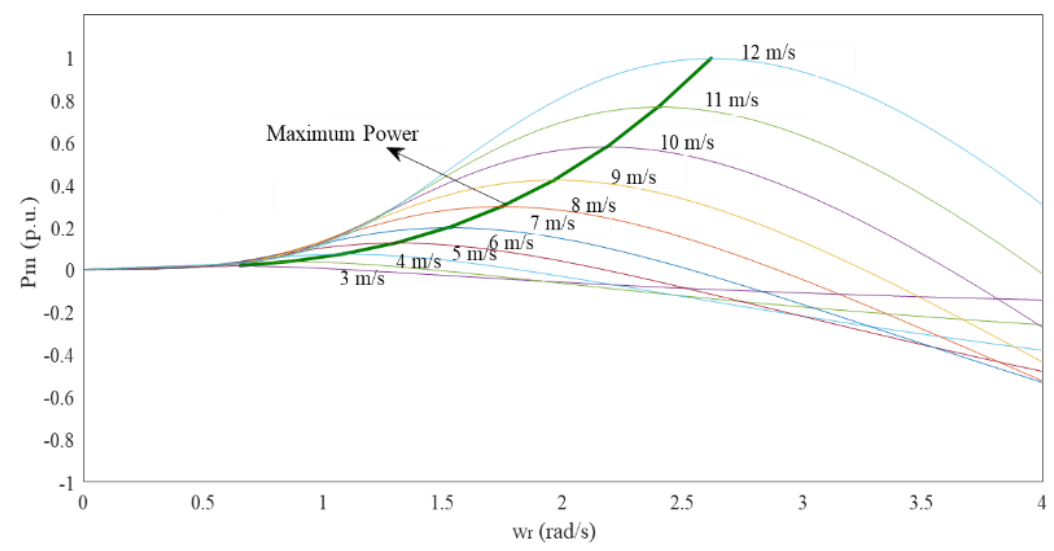

Figure 5. Proposed RBFNN training based maximum power curve of DE algorithm

The interpolation issues in a multidimensional space depending on many centers as data points were solved by RBFNN, which was first present by Powell. Its significant characteristic is fast and in a network, a linear learning algorithm capable of showing complex non-linear charts are used. Moreover, the generalization characteristics of RBFNN are also to improve [26]. This neural network designs as following steps, firstly we run the initial program with the DE algorithm based MPPT and make a detailed look up table of input and output data. Secondly, implement to train the RBFNN based this data and using this neural network to replace old MPPT block. The RBFNN has three layers. The first layer is input player that has only corresponded the input signal. It's possible that there are multiple variables, each of which corresponds to a separate neuron. The input layer neurons' outputs are used to deliver values to each of the hidden layer neurons' inputs. The structure of the RBFNN shows in Figure 6 (a) to realize data processing duties, which contains an input, an output, and a hidden layer. The (8) represents the net input and output of the input layer and Figure 6 (b) shows the block diagram of the MPPT algorithm in Matlab.

$$
\left.\begin{array}{l}
n e t_{j}^{1}=x_{i}^{1} \\
y_{1 \mathrm{j}}^{1}=f^{1}\left(n e t_{j}^{1}\right)=\left(x_{i}^{1}\right)
\end{array}\right\}_{\mathrm{j}=1 . . \mathrm{n} ; \mathrm{i}=1,2}
$$

Where $\mathrm{x}_{i}^{l}$ is the input layer, the net sum of nodes is represented by $f\left(\mathrm{x}_{i}{ }_{i}\right)$ which is fed to the hidden layer.

The second layer is a hidden layer that is nonlinear and uses Gaussian functions. It can contain a large number of neurons. This layer's selection of neurons is a difficult undertaking. For the selection of neurons in the hidden layer, we proposed a data structure-preserving criterion technique. Each neuron in the hidden layer is made up of an RBF centered at a point, depending on the complexity of the input/output variables. The basic functions, which are dependent on the parameters $\left\{w^{l}{ }_{l j}, b_{j}^{l}\right\}$ and input activations $\left\{\mathrm{x}_{j}^{l}\right\}$ determine the hidden unit activations. For each dimension, the RBF function's spread (radius) may be different. Figures 6 (c) and 6 (d) shows the structure of Layer 1. The best structure for an RBFNN is determined by the application area. The network's training process determines the network's centers and spreads. The hidden layer's net input and output are shown.

$$
\left.\begin{array}{l}
n e t_{j}^{2}=\sum_{j} w_{1 \mathrm{j}}^{1} y_{1 \mathrm{j}}^{1} \\
y_{1 \mathrm{j}}^{2}=f^{2}\left(w_{1 \mathrm{j}}^{1} y_{1 \mathrm{j}}^{1}+b_{j}^{1}\right)
\end{array}\right\}_{\mathrm{j}=1 \ldots \mathrm{n}}
$$



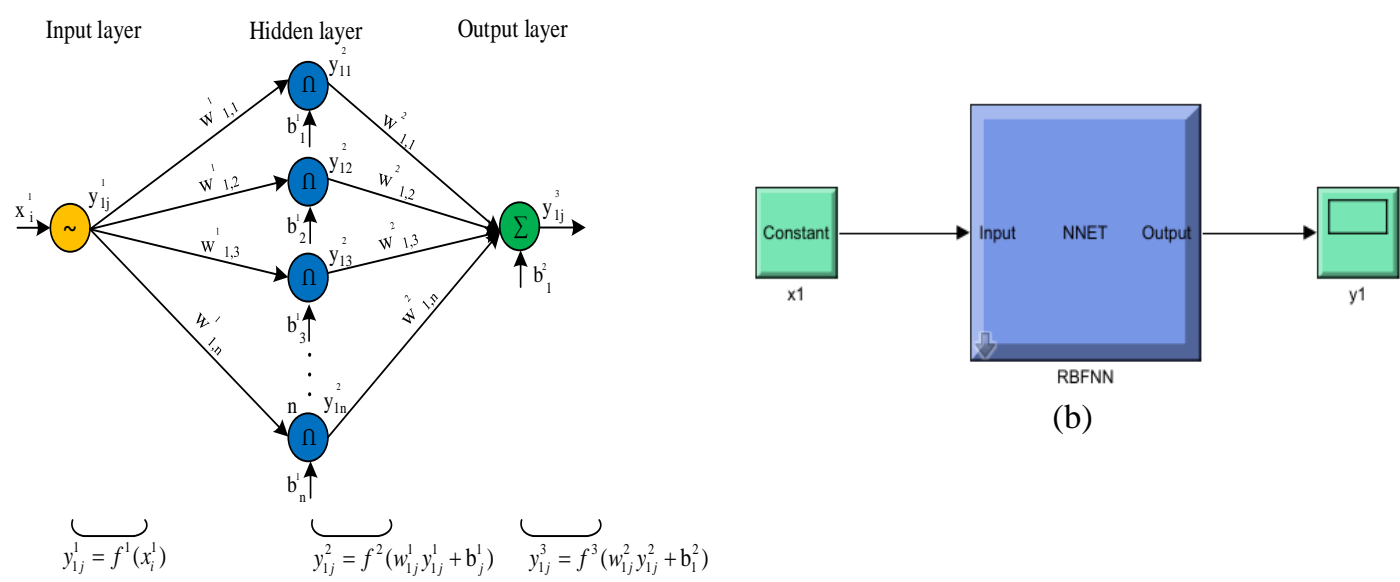

(b)

(a)

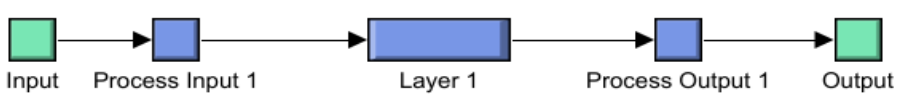

(c)

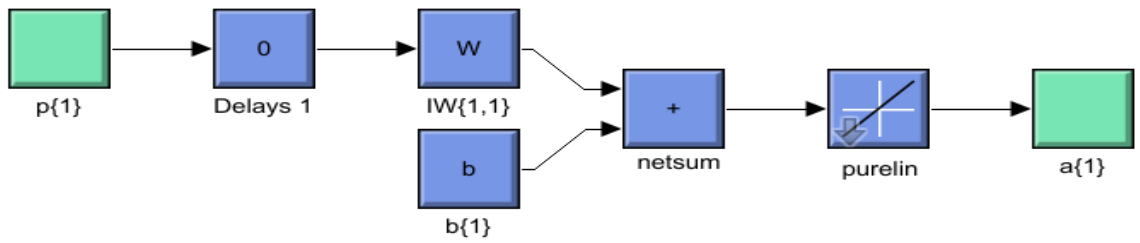

(d)

Figure 6. Design and implement RBFNN controller, (a) block diagram of MPPT method using RBFNN; (b) RBFNN block in MATLAB; (c) the structure of RBFNN in MATLAB; (d) the structure of RBFNN in MATLAB

Where $w^{l}{ }_{l j}$ is the weights which connect the input layer and hidden layer, $b_{j}^{l}$ is the bias terms of the hidden layer. Thirdly, The Gaussian outputs are combined by the linear layer. During training, only the weights between the hidden and output layers are modified and calculated using Moore-Penrose generalized pseudo-inverse [27].

$$
\left.\begin{array}{l}
n e t_{j}^{3}=\sum_{j} w_{1 \mathrm{j}}^{2} y_{1 \mathrm{j}}^{2} \\
y_{1 \mathrm{j}}^{3}=f^{3}\left(w_{1 \mathrm{j}}^{2} y_{1 \mathrm{j}}^{2}+b_{1}^{2}\right)
\end{array}\right\}_{\mathrm{j}=1 \ldots \mathrm{n}}
$$

Where $w^{2}{ }_{l j}$ is the weights which connect the hidden layer and output layer, $b_{j}^{2}$ is the bias terms of the output layer. Today RBFNN research has been continuously increasing and becoming more ubiquitous in several application areas. RBFNN broadly consists of three layers feed-forward neural network [24], [25]. The three-layer RBFNN employed in this section has been demonstrated to be a universal approximation. [26]. The RBFNN's overall input-output mapping is given by,

$$
\frac{d \omega_{r}}{d t}=b+\sum_{j=1}^{n} v_{j} \exp \left(-\frac{\left\|x-C_{j}\right\|^{2}}{\beta_{j}^{2}}\right)
$$

where $x=\left[v_{w}\right]$ are the input vector, $C_{j} € R_{m}$ is the center of the $j_{t h}$ RBF units in the hidden layer, $\mathrm{n}$ is the number of RBF units, $b$ and $v_{j}$ are the bias term and the weight between hidden and $y=\left[w_{r}\right]$ output layers respectively of the RBFNN that represents the wind turbine rotational speed. 


\section{4. $\quad d$-AXIS STATOR CURRENT CONTROL TECHNIQUES}

\subsection{ZDC}

The ZDC is the most widely utilized control technique applied to industry because of its simplicity [2]. In order to implement this control technique, $d$-axis stator current is set to zero. So, the relationship between torque and current can be linearized.

\subsection{UPF}

Under this control law, the power factor angle is always kept at unity. This reason would lead to a cost effective solution for the BTB converter. This is one of the most important issues for a megawatt-scale wind energy conversion system [3]. (12) shown this implementation of this control law by setting the reactive power equal zero and illustrated in Figure 7, as shown in (5) substitutes into (12).

$$
u_{\mathrm{ds}} i_{\mathrm{qs}}-u_{\mathrm{qs}} i_{\mathrm{ds}}=0
$$

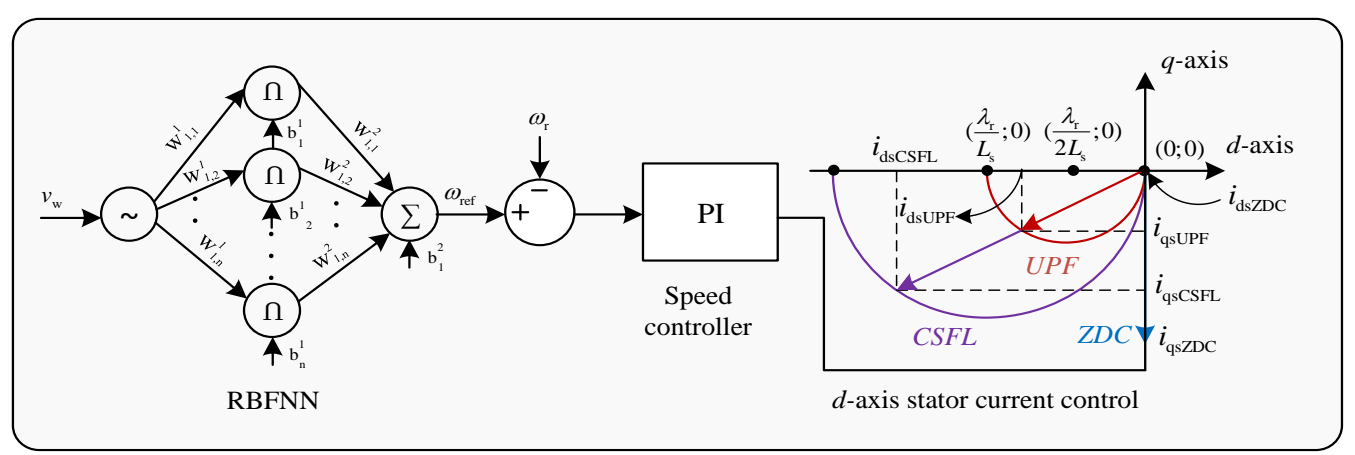

Figure 7. Proposed MPPT technique and block diagram $d$ axis stator current control

$$
i_{\mathrm{ds}}=-\frac{\lambda_{r}}{2 L_{s}}+\sqrt{\left(\frac{\lambda_{r}}{2 L_{s}}\right)^{2}-\left(i_{\mathrm{qs}}\right)^{2}}
$$

In (13) shows that the current of $q$-axis stator should satisfy the following constraint

$$
i_{\mathrm{qs}} \leq \frac{\lambda_{\mathrm{r}}}{2 L_{\mathrm{s}}}
$$

\subsection{CSFL}

In order to overcome increasing stator flux linkage (saturation of the stator yoke) when the torque value is increased, the CSFL must be applied. One of the most characteristics of the CSFL control is high steady-state efficiency, good capacity factor, and tiny required power converter capacity. In a similar way with implementing other d-axis stator current control techniques, the amplitude of the stator flux vector is kept constant and equal to the permanent magnet flux shown as (15). This control technique will be done and it is illustrated in Figure 7 [28].

$$
\begin{aligned}
& \left|\lambda_{s}\right|=\sqrt{\left(L_{s} i_{\mathrm{ds}}+\lambda_{r}\right)^{2}+\left(L_{s} i_{\mathrm{qs}}\right)^{2}}=\lambda_{r} \\
& i_{d s}=-\frac{\lambda_{r}}{L_{s}}+\sqrt{\left(\frac{\lambda_{r}}{L_{s}}\right)^{2}-\left(i_{q s}\right)^{2}}
\end{aligned}
$$

In (16) is existed, the current of $q$-axis stator should satisfy the following constraint

$$
i_{\mathrm{qs}} \leq \frac{\lambda_{r}}{L_{s}}
$$

In this case, the analysis can be summarized as the main feature of ZDC control is high cost under wind speed variations due to poor efficiency and the high reactive power: 
- The main feature of UPF control reduced the cost of the power circuit because of its small size, though it is high performance under wind speed variations. This is one of the significant considerations for megawatt-level wind turbine capacity;

- A proposed technique for controlling the MSC of vector-controlled PMSG wind turbine is CSFL control because of good characteristic and high power factor.

\section{SIMULATION RESULTS}

In this paper, The RBFNN controller based MPPT method applied to PMSG has been implemented in MATLAB under variable wind speed. In order to evaluate and analyze the proposed solution's performance, RBFNN controller based on the average and standard deviation (SD) in Table 2 that is relationship between the turbine powers at variable rotor speed and the net sum of nodes is 10 . When the error value reaches the permitted value, the training ends (performance $=0.00001$ ) or lessons reach the allowable value (epoch=100). The process of network training is depicted in Figure 8. The network training chart presents network-training process, which occurs 100 times before stopping. Simultaneously, the finest training results will be 0.00015265 using the RBFNN block takes the place of the old block of the MPPT algorithm and is depicted in Figure 7.

Table 2. Data of RBFNN

\begin{tabular}{|c|c|c|c|c|c|c|c|c|c|c|c|}
\hline Signal & & 1 & 2 & 3 & 4 & 5 & 6 & 7 & 8 & 9 & 10 \\
\hline \multirow{2}{*}{ RBFNN } & Average & $\begin{array}{c}2.08 \mathrm{e}- \\
14\end{array}$ & $1.01 \mathrm{e}+1$ & $2.43 \mathrm{e}+1$ & $4.07 \mathrm{e}+1$ & $\begin{array}{c}1.35 \mathrm{e}- \\
3\end{array}$ & $\begin{array}{c}8.06 \mathrm{e}- \\
14\end{array}$ & $\begin{array}{c}2.41 \mathrm{e}- \\
11\end{array}$ & $1.4 \mathrm{e}-19$ & $8.05 \mathrm{e}-1$ & $\begin{array}{c}3.72 \mathrm{e}- \\
1\end{array}$ \\
\hline & SD & 0 & $1.3 \mathrm{e}+1$ & $3.85 \mathrm{e}+1$ & $1.62 \mathrm{e}+2$ & $0 \mathrm{e}+0$ & $\begin{array}{c}5.65 \mathrm{e}- \\
14\end{array}$ & $\begin{array}{c}1.03 \mathrm{e}- \\
22\end{array}$ & $\begin{array}{c}3.64 \mathrm{e}- \\
36\end{array}$ & $1.79 \mathrm{e}-3$ & $0 \mathrm{e}+0$ \\
\hline Signal & & 11 & 12 & 13 & 14 & 15 & 16 & 17 & 18 & 19 & 20 \\
\hline \multirow{2}{*}{ RBFNN } & Average & $\begin{array}{c}3.45 \mathrm{e}- \\
10\end{array}$ & $3.1 \mathrm{e}-1$ & $7.12 \mathrm{e}+1$ & $2.33 \mathrm{e}+0$ & $5.3 \mathrm{e}-2$ & $1.38 \mathrm{e}-6$ & $3.7 \mathrm{e}-11$ & $\begin{array}{c}9.07 \mathrm{e}- \\
20\end{array}$ & $3.33 \mathrm{e}+0$ & 0 \\
\hline & SD & $\begin{array}{c}4.95 \mathrm{e}- \\
12\end{array}$ & $4.52 \mathrm{e}-1$ & $5.39 \mathrm{e}-1$ & $1.99 \mathrm{e}+0$ & $\begin{array}{c}6.7 \mathrm{e}- \\
12\end{array}$ & $1.21 \mathrm{e}-7$ & $\begin{array}{c}1.78 \mathrm{e}- \\
12\end{array}$ & $6.8 \mathrm{e}-23$ & $1.07 \mathrm{e}-1$ & 0 \\
\hline
\end{tabular}

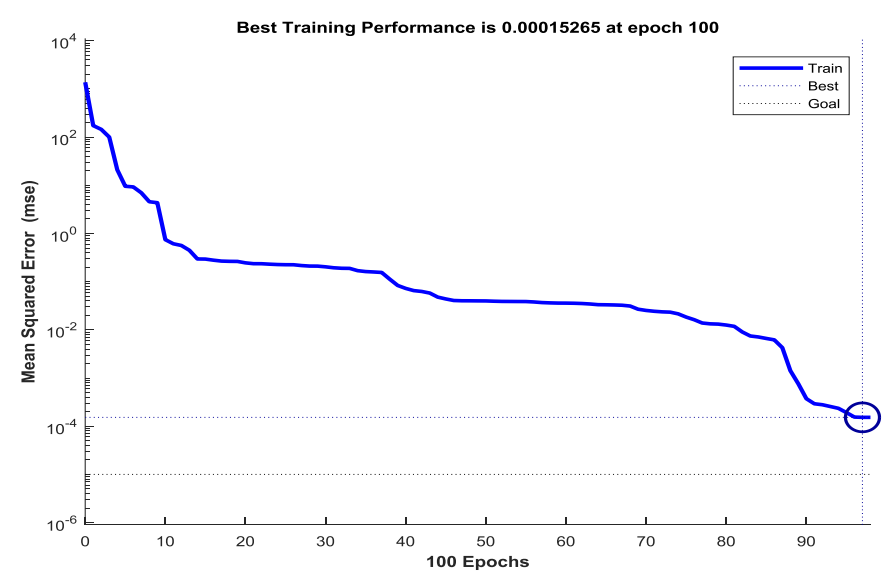

Figure 8. Network training graph

The simulation results in Matlab, which assess and compare the strong points and weak points of the proposed stator current control techniques and RBFNN based on the MPPT method. The effectiveness of stator current control techniques is considered under wind speed variation. Tables 3 and 4 list the PMSG wind turbine's parameters. Figure 9 (a) is depicted the variable wind speed from $3 \mathrm{~m} / \mathrm{ses}$ to $12 \mathrm{~m} / \mathrm{sec}$ over a period of $50 \mathrm{sec}$. In order to produce maximum power and be avoided demagnetization of the permanent magnet, the $d$ axis stator current is set up at zero. The simulation results of the stator current on $d$ axis $\left(i_{d s Z D C}\right.$, $\left.i_{d S U P F}, i_{d S C S F L}\right)$ in three control techniques are illustrated in Figure 9 (b). In Figure 9 (b) shows that the highest amplitude value of stator current on $d$ axis is the UPF control technique, oppositely is ZDC control technique. The disadvantage of the UPF control technique must select wire with large cross-sectional for MSC because of the high cost. On the other hand, the stator current on $q$ axis $\left(i_{q s Z D C}, i_{q S U P F}, i_{q s C S F L}\right)$ of three control techniques are same value $\left(i_{q S Z D C}=i_{q s U P F}=i_{q s C S F L}\right)$ under wind speed variation and illustrated in Figure 9 (c). 
The stator fluxes $\left(\lambda_{Z D C}, \lambda_{U P F}, \lambda_{C S F L}\right)$ are illustrated in Figure 9 (d). The stator flux of the CSFL control technique always is constant while the stator flux of the ZDC control technique is the highest worth and the stator flux of the UPF control technique is the lowest worth under different wind speeds.

Table 3. Turbine parameters [2]

\begin{tabular}{lrr}
\hline \multicolumn{1}{c}{ Description } & Parameter & \multicolumn{1}{c}{ Value } \\
\hline Transparent power & $S_{n}$ & $2.2 \mathrm{MW}$ \\
Current & $I_{n}$ & $2606 \mathrm{~A}$ \\
Voltage & $u_{n}$ & $690 \mathrm{~V}$ \\
DC voltage & $V_{d c}$ & $1200 \mathrm{~V}$ \\
Rotating speed & $\omega_{m}$ & $2.355 \mathrm{rad} / \mathrm{s}$ \\
Number of poles & $Z_{p}$ & $26 \mathrm{~N} . \mathrm{m}$ \\
Moment & $T_{e}$ & $934.1 \mathrm{kNm}$ \\
Viscous damping & $B$ & $0.0041 \mathrm{Nms}$ \\
Stator phase resistance & $R_{s}$ & $0.8 \mathrm{e}-3 \Omega$ \\
Stator phase inductance & $L_{s}$ & $1.67 \mathrm{mH}$ \\
Flux linkage & $\lambda_{r}$ & $9.18 \mathrm{~Wb}$ \\
Inertia of turbine rotor & $J_{n}$ & $0.5 \mathrm{e} 6 \mathrm{~kg} . \mathrm{m}^{2}$ \\
& $c_{1}$ & 0.5176 \\
& $c_{2}$ & 116 \\
The approximate & $c_{3}$ & 0.4 \\
coefficient values & $c_{4}$ & 5 \\
& $c_{5}$ & 21 \\
& $c_{6}$ & 0.0068 \\
\hline
\end{tabular}

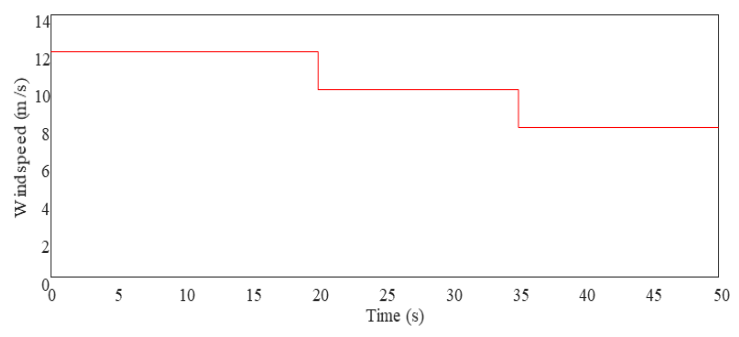

(a)

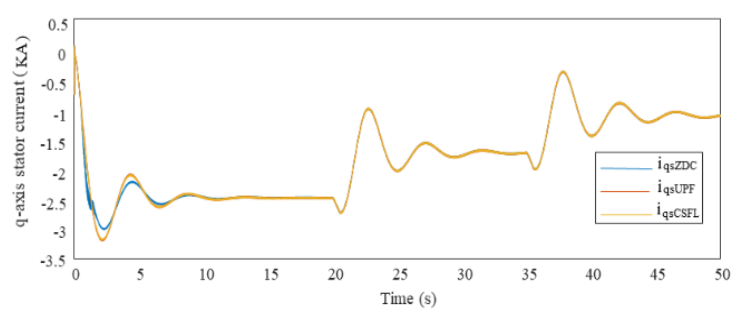

(c)
Table 4. Generator parameters [2]

\begin{tabular}{ccc}
\hline Depiction & Parameter & Value \\
\hline Rated power & $P_{n}$ & $2 \mathrm{MW}$ \\
Rotating speed & $\omega_{m}$ & $2.355 \mathrm{rad} / \mathrm{s}$ \\
Alternator rotor inertia & $J_{m}$ & $0.25 \mathrm{e} 3 \mathrm{~kg} \cdot \mathrm{m}^{2}$ \\
Blades length & $R$ & $37.1 \mathrm{~m}$ \\
wind speed & $v_{w}$ & $12 \mathrm{~m} / \mathrm{sec}$ \\
\hline
\end{tabular}

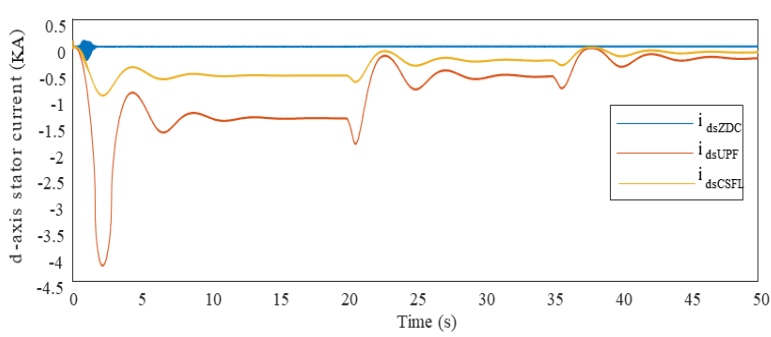

(b)

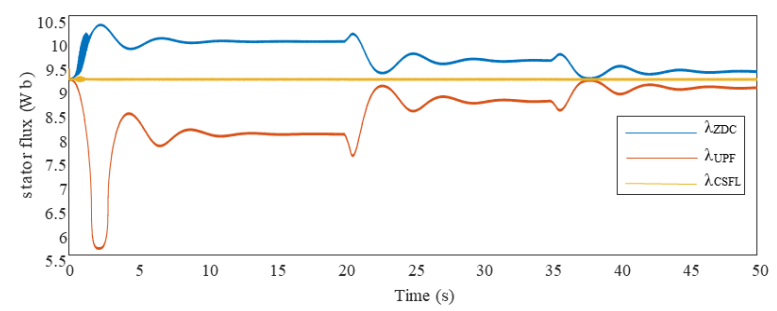

(d)

Figure 9. Wind energy conversion system: (a) wind speed; (b) $d$-axis stator current; (c) $q$-axis stator current; (d) stator flux

Figure 10 shows the active power $\left(P_{Z D C}, P_{U P F}, P_{C S F L}\right)$ and reactive power $\left(Q_{Z D C}, Q_{U P F}, Q_{C S F L}\right)$ of three control methods, in that the active power is approximately the same value $\left(P_{Z D C}=P_{U P F}=P_{C S F L}\right)$ because of according to (6) torque or active power are proportional with $q$-axis stator current (as mentioned above, the Simulink results in Figure 9 (c) shows that the $q$-axis stator current in three control methods is of the same value). Furthermore, the reactive power in the UPF control method is always zero, the highest value is reactive power in the ZDC control method. In Figure 11. The highest value of apparent power is the ZDC control technique at $12 \mathrm{~m} / \mathrm{sec}$ and this is its drawback due to a high cost. The opposite is the UPF control technique, which has the lowest value. The apparent power of the ZDC control technique continues the highest while the UPF control technique and CSFL control technique are the same value over a period of 8 $\mathrm{m} / \mathrm{sec}$ to $11 \mathrm{~m} / \mathrm{sec}$. Finally, the apparent power of the three techniques is the same value at a wind speed below $8 \mathrm{~m} / \mathrm{sec}$. The opposite of the highest value of the capacity factor in the UPF technique $\left(\theta_{U P F}\right)$ is the ZDC control technique $\left(\theta_{\mathrm{ZDC}}\right)$ while the power factor of the CSFL control technique $\left(\theta_{C S F L}\right)$ has the middle 
value. It is depicted in Figure 12. According to Figure 13, the stator current of three control techniques $\left(i_{s Z D C}\right.$, $\left.i_{S U P F}, i_{S C S F L}\right)$ has two instances. Over a period of $8 \mathrm{~m} / \mathrm{sec}$ to $11 \mathrm{~m} / \mathrm{sec}$, the highest value of stator current is the UPF control technique $\left(i_{S U P F}\right)$ and this is its drawback due to a high cost (it should choose the wire with a large cross-section for MSC). The opposite is the ZDC control technique $\left(i_{s Z D C}\right)$, which has the lowest value. When the wind speed is less than $8 \mathrm{~m} / \mathrm{sec}$, the stator current of three control techniques $\left(i_{S Z D C}, i_{s U P F}, i_{S C S F L}\right)$ has the same value.

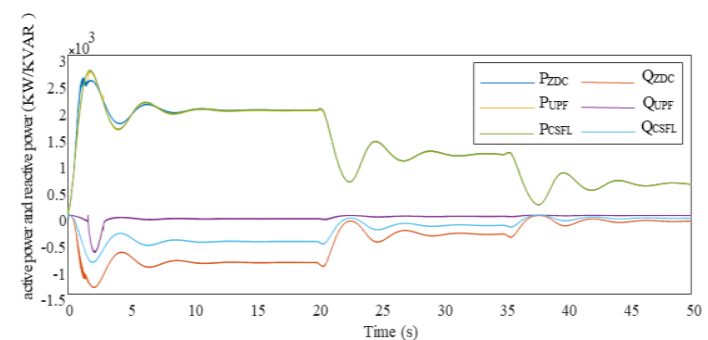

Figure 10. Active power and reactive power

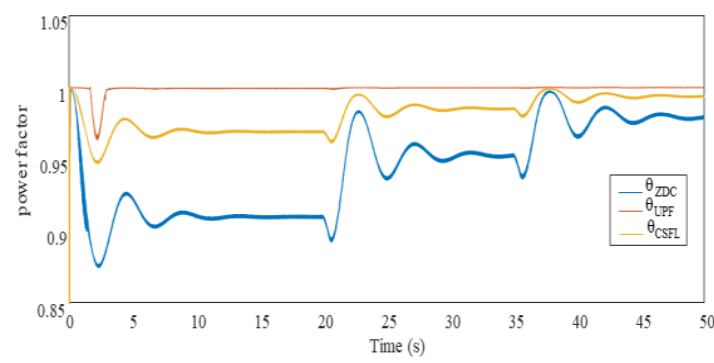

Figure 12. Power factor

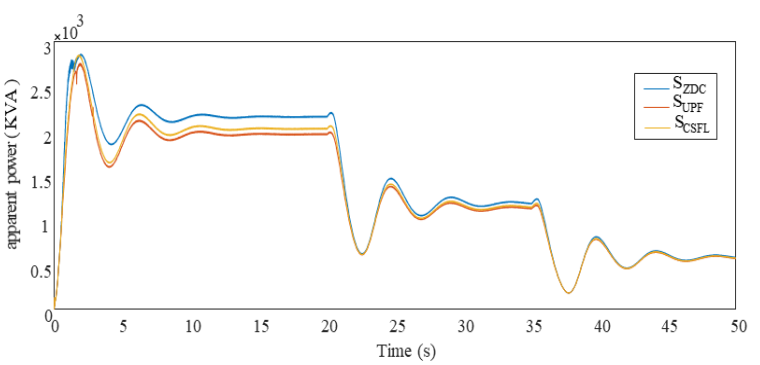

Figure 11. Apparent power

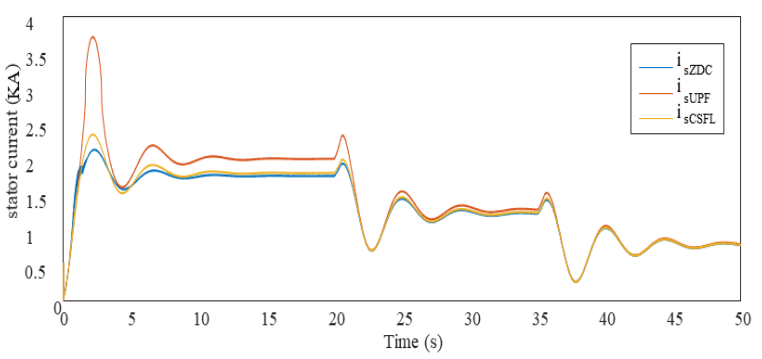

Figure 13. RMS stator current

\section{CONCLUSION}

In this paper, a new radial basis function neural network maximum power point tracking controller based on differential evolution algorithm for machine side converter of permanent magnet synchronous alternator is presented. The proposed controller was designed and applied successfully to permanent magnet synchronous generator wind turbines. The simulation results show that the controller has high accuracy and stability in tracking the maximum power point and increases the power of permanent magnet synchronous generator wind turbines. In addition, three $d$ axis stator current, zero $d$ axis stator current, unity power factor, and constant stator flux-linkage have been studied. Generally, the constant stator flux-linkage method can be reduced costly without the hardware. In future work, a low-cost processor-in-the-loop platform will be applied to experimental verification of the proposed approach.

\section{ACKNOWLEDGEMENTS}

This research received funding from the Industrial University of Ho Chi Minh City, Vietnam.

\section{REFERENCES}

[1] V. Perelmuter, "Renewable energy systems: Simulation with Simulink and SimPowerSystems," CRC Press, 2016.

[2] V. Yaramasu, B. Wu, P. C. Sen, S. Kouro and M. Narimani, "High-power wind energy conversion systems: Stateof-the-art and emerging technologies," Proceedings of the IEEE, vol. 103, no. 5, pp. 740-788, May 2015, doi: 10.1109/JPROC.2014.2378692.

[3] V. Yaramasu, and Bin Wu, "Model predictive control of wind energy conversion systems," Wiley-IEEE Press, 2017.

[4] M. J. Duran, F. Barrero, A. Pozo-Ruz, F. Guzman, J. Fernandez and H. Guzman, "Understanding Power Electronics and Electrical Machines in Multidisciplinary Wind Energy Conversion System Courses," IEEE Transactions on Education, vol. 56, no. 2, pp. 174-182, May 2013, doi: 10.1109/TE.2012.2207119. 
[5] H. Polinder, J. A. Ferreira, B. B. Jensen, A. B. Abrahamsen, K. Atallah and R. A. McMahon, "Trends in Wind Turbine Generator Systems," IEEE Journal of Emerging and Selected Topics in Power Electronics, vol. 1, no. 3, pp. 174-185, Sept. 2013, doi: 10.1109/JESTPE.2013.2280428.

[6] Ramji Tiwari, and N. Ramesh Babu, "Recent developments of control strategies for wind energy conversion system," Renewable and Sustainable Energy Reviews, vol. 66, pp 268-285, 2016, doi: 10.1016/j.rser.2016.08.005.

[7] M. A. Beniss, H. E. Moussaoui, T. Lamhamdi, and H. El Markhi, "Performance analysis and enhancement of direct power control of DFIG based wind system," International Journal of Power Electronics and Drive System IJPEDS, vol. 12, no. 2, pp. 1034-1044, 2021, doi: 10.11591/ijpeds.v12.i2.pp1034-1044.

[8] V. Yaramasu, A. Dekka, M. J. Durán, S. Kouro, and B. Wu, "PMSG - based wind energy conversion systems: survey on power converters and controls," IET Electric Power Applications, vol. 11, no. 6, pp. 956-968, 2017, doi: 10.1049/iet-epa.2016.0799.

[9] M. Rahimi, "Mathematical modeling, dynamic response analysis, and control of PMSG- based wind turbines operating with an alternative control structure in power control mode," International Transactions on Electrical Energy Systems, vol. 27, no. 12, pp. 1-18, 2017, doi: 10.1002/etep.2423.

[10] B. Liu, Z. Li, X. Zhang, X. Dong and X. Liu, "Impedance-Based Analysis of Control Interactions in Weak-GridTied PMSG Wind Turbines," IEEE Journal on Emerging and Selected Topics in Circuits and Systems, vol. 11, no. 1, pp. 90-98, March 2021, doi: 10.1109/JETCAS.2020.3027608

[11] F. Bakhtiari and J. Nazarzadeh, "Optimal Estimation and Tracking Control for Variable-speed Wind Turbine with PMSG," Journal of Modern Power Systems and Clean Energy, vol. 8, no. 1, pp. 159-167, January 2020, doi: 10.35833/MPCE.2018.000365.

[12] H. H. H. Mousa, A. R. Youssef, E. E. M. Mohamed, "Optimal power extraction control schemes for five-phase PMSG based wind generation systems," Engineering Science and Technology, an International Journal, vol. 23, no. 1, pp 144-155, 2020, doi: 10.1016/j.jestch.2019.04.004.

[13] N. Z. Laabidine, A. Errarhout, C. E. Bakkali, K. Mohammed, B. Bossoufi, "Sliding mode control design of wind power generation system based on permanent magnet synchronous generator," International Journal of Power Electronics and Drive System IJPEDS, vol. 12, no. 1, pp. 393-403, 2021, doi: 10.11591/ijpeds.v12.i1.pp393-403.

[14] K. Noussi, A. Abouloifa, H. Katir, I. Lachkar, and F. Giri, "Nonlinear control of grid-connected wind energy conversion system without mechanical variables measurements," International Journal of Power Electronics and Drive System IJPEDS, vol. 12, no. 2, pp. 1139-1149, 2021, doi: 10.11591/ijpeds.v12.i2.pp1139-1149.

[15] R. Subramaniam and Y. H. Joo, "Passivity-Based Fuzzy ISMC for Wind Energy Conversion Systems With PMSG," IEEE Transactions on Systems, Man, and Cybernetics: Systems, vol. 51, no. 4, pp. 2212-2220, 2021, doi: 10.1109/TSMC.2019.2930743.

[16] N. Tidjani, and A. Guessoum, "Augmented robust T-S fuzzy control based PMSG wind turbine improved with $H \infty$ performance," International Journal of Power Electronics and Drive System IJPEDS, vol. 12, no. 1, pp. 585-596, 2021, doi: 10.11591/ijpeds.v12.i1.pp585-596.

[17] M. B. HemanthKumar, B. Saravanan, P. Sanjeevikumar, F. Blaabjerg, "Review on control techniques and methodologies for maximum power extraction from wind energy systems," IET Renewable Power Generation, vol. 12, no. 14, pp. 1609-1622, 2018, doi: 10.1049/iet-rpg.2018.5206.

[18] A. Ghaffari, M. Krstić and S. Seshagiri, "Power Optimization and Control in Wind Energy Conversion Systems Using Extremum Seeking," IEEE Transactions on Control Systems Technology, vol. 22, no. 5, pp. 1684-1695, 2014, doi: 10.1109/TCST.2014.2303112.

[19] R. Sitharthan, M. Karthikeyan, D. S. Sundar and S. Rajasekaran, “Adaptive hybrid intelligent MPPT controller to approximate effectual wind speed and optimal rotor speed of variable speed wind turbine," ISA Transactions, vol. 96, pp 479-489, 2020, doi: 10.1016/j.isatra.2019.05.029.

[20] E. C. Navarrete, M. T. Perea, J. C. J. Correa, R. V. C. Serrano and J. G. R. Moreno, "Expert Control Systems for Maximum Power Point Tracking in a Wind Turbine with PMSG: State of the Art," Applied Sciences, vol. 9, no. 12, pp. 1-24, 2019, doi: 10.3390/app9122469.

[21] S. Das and P. N. Suganthan, "Differential Evolution: A Survey of the State-of-the-Art," IEEE Transactions on Evolutionary Computation, vol. 15, no. 1, pp. 4-31, Feb. 2011, doi: 10.1109/TEVC.2010.2059031.

[22] A. K. Qin, V. L. Huang and P. N. Suganthan, "Differential Evolution Algorithm With Strategy Adaptation for Global Numerical Optimization," IEEE Transactions on Evolutionary Computation, vol. 13, no. 2, pp. 398-417, 2009, doi: 10.1109/TEVC.2008.927706.

[23] M. Aly and H. Rezk, "A Differential Evolution-Based Optimized Fuzzy Logic MPPT Method for Enhancing the Maximum Power Extraction of Proton Exchange Membrane Fuel Cells," IEEE Access, vol. 8, pp. 172219-172232, 2020, doi: 10.1109/ACCESS.2020.3025222.

[24] M. T. Hagan, H. B. Demuth, M. H. Beale, and O. D. Jesús, "Neural network design", Martin Hagan, 2nd Edition, 2014.

[25] Jinkun Liu, "Radial Basis Function (RBF) Neural Network Control for Mechanical Systems," Springer 2013.

[26] H. Jafarnejadsani, J. Pieper, J. Ehlers, "Adaptive Control of a Variable-Speed Variable-Pitch Wind Turbine Using Radial-Basis Function Neural Network," IEEE Transactions on Control Systems Technology, vol. 21, no. 6, pp. 2264-2272, 2013, doi: 10.1109/TCST.2012.2237518.

[27] E. Assareh, M. Biglari, "A novel approach to capture the maximum power from variable speed wind turbines using PI controller, RBF neural network and GSA evolutionary algorithm," Renewable and Sustainable Energy Reviews, vol. 51, pp. 1023-1037, 2015, doi: 10.1016/j.rser.2015.07.034.

[28] M. P. Kazmierkowski, R. Krishnan, and Frede Blaabjerg, "Control in Power Electronics: Selected Problems," Academic Press; 1st Edition, 2002. 